\title{
Experimental Evaluation of the Mechanical Properties of Recycled Low Density Polyethylene/Bean Pod Ash Particulate Bio-Composites
}

\author{
M. C. Ekwedigwe, E. E. Nnuka, C. U. Atuanya* \\ Department of Metallurgical and Materials Engineering, Nnamdi Azikiwe University, Awka, Nigeria \\ Email: *Atueye2003@yahoo.co.uk
}

Received 1 July 2015; accepted 21 August 2015; published 24 August 2015

Copyright (C) 2015 by authors and Scientific Research Publishing Inc.

This work is licensed under the Creative Commons Attribution International License (CC BY). http://creativecommons.org/licenses/by/4.0/

(c) (i) Open Access

\section{Abstract}

The evaluation of bean pod ash particles on the properties of recycled low density polyethylene (RLDPE) composites was studied. The RLDPE/bean pod ash particles (CBPp) composites were produced using compounding and compressive moulding techniques. Factorial design of experiment and analysis of variance (ANOVA) were employed for optimization. The mechanical properties and microstructure of the composites were determined. The results obtained showed that the optimum values of flexural strength were obtained at $140^{\circ} \mathrm{C}, 12$ minutes, $40 \mathrm{wt} \% \mathrm{CBPp}$ and $6 \mathrm{Mpa}$. The hardness values, tensile and bending strengths of the composite increased by the addition of beans pod ash particles to RLDPE composites. Compressive properties of RLDPE matrix and composites were 13.00 and $18.25 \mathrm{~N} / \mathrm{mm}^{2}$. The fairly uniform distribution of the bean pod ash particles in the microstructure of the composites is the major factor responsible for the improvement in the mechanical properties. The obtained results of the developed composites have shown that the beans pod waste could be used as a biodegradable eco-friendly reinforcement.

\section{Keywords}

Microstructure, Mechanical Properties, Statistical Studies and Composites Fabrication

\section{Introduction}

In recent years there is a perceived shortage of wood fibre for composite products due to competition for fibre

\footnotetext{
*Corresponding author.
}

How to cite this paper: Ekwedigwe, M.C., Nnuka, E.E. and Atuanya, C.U. (2015) Experimental Evaluation of the Mechanical Properties of Recycled Low Density Polyethylene/Bean Pod Ash Particulate Bio-Composites. Journal of Minerals and Materials Characterization and Engineering, 3, 362-372. http://dx.doi.org/10.4236/jmmce.2015.35039 
by pulp mills, reduced harvest and diminished log quality. Also, there is pressure from environmentalists to reduce forest use and regulatory legislation pending on disposal of agro-fibres [1] [2]. For example, any potential to reduce field burning is an environmental benefit and helps address the issue of restricted open burning. There are a total of about 365,000,000 dry tones of all non-wood fibre produced in North America and Africa each year [3]. While it is estimated that only about $1 / 3$ of the cereal straw produced annually is available for nonagricultural uses [4], the available agricultural residues could more than replace all of the wood based composites presently produced on the basis of volume only. There may be potential to sell agricultural residues based composite products as a premium product or alternatively to have additional marketing pluses based on environmental issues (formaldehyde free, sustainability of the product, green certification) and properties (moisture resistance, machining properties, low density). Based on the fore going, this present study is looking into the possibility of using beans pod particle in the production of polymer bio-composites.

During the past few decades, many polymer composites have been prepared and combined with various types of synthetic reinforcing fillers in order to improve the mechanical properties and obtain the characteristics demanded in actual applications [5]. The use of natural filler for the reinforcement of the composites has received increasing attention both by the academic sector and the industry. Natural filler has many significant advantages over synthetic filler and fibres such as their light-weight, low cost, ability to reduce abrasion of machinery and also non-toxicity. Currently, many types of natural fillers have been investigated to be used in the industry including flax, hemp, wood, wheat, barley, and oats [6]. They are now fast evolving as potential alternatives to inorganic or synthetic materials for various applications as building materials and automotive components [7] [8].

There are lots of waste materials from beans pod and water sachets (recycled low density polyethylene) found in Nigerian environment. These constitute nuisance to the environment. Our desire in this study is to produce and evaluate the mechanical properties of recycled low density polyethylene/bean pod ash particulate biocomposites.

\section{Experimental Procedure}

\subsection{Experimental Design}

Factorial design and linear regression techniques have been widely used in the engineering analysis. These techniques consist of plan of experiments with objective of acquiring data in a controlled way, executing these experiments in order to obtain information about the behaviour of a given process [9]. Two levels of each of the four factors were used for the optimization analysis. The levels for the four factors are shown in Table 1 . The treatment combinations for the two levels and their factors are tabulated in Table 2. Representing the flexural strength by $\mathrm{F}$, the response function can be expressed by equation below:

$$
W=f(A, B, C, D)
$$

where: $A=$ temperature, $B=$ time, $C=$ reinforcer/polymer content, $D=$ pressure.

The model selected includes the effects of main variables first-order and second-order interactions of all variables. Hence the general model is written as:

$$
F=b_{0}+b_{1} A+b_{2} B+b_{3} C+b_{4} D+b_{5} A B+b_{6} A C+b_{7} A D
$$

were $b_{0}$ is average response of $Y$ and $b_{1}, b_{2}, b_{3}, b_{4}, b_{5}, b_{6}, b_{7}, b_{8}$ are coefficients associated with each variable $A$, $B, C, D$ and interaction.

Table 1. Actual and coded values of the independent variables.

\begin{tabular}{ccccc}
\hline \multirow{2}{*}{ Variables } & \multicolumn{2}{c}{ Actual value } & \multicolumn{2}{c}{ Coded value } \\
\cline { 2 - 5 } & Low level & High value & Low level & High value \\
\hline Temperatures $\left({ }^{\circ} \mathrm{C}\right), A$ & 140 & 160 & -1 & +1 \\
Time (minutes), $B$ & 6 & 12 & -1 & +1 \\
Reinforcer/polymer (wt\%), C & $40 / 60$ & $60 / 40$ & -1 & +1 \\
Pressure (Mpa), $D$ & 3 & 6 & -1 \\
\hline
\end{tabular}


Table 2. Factorial design of the flexural strength showing treatment combination.

\begin{tabular}{ccccc}
\hline S/No. & Temperature $\left({ }^{\circ} \mathrm{C}\right)$ & Time (minutes) & Reinforcer/polymer (wt\%) & Pressure (Mpa) \\
\hline S1 & 140 & 12 & $40 / 60$ & 6 \\
S2 & 160 & 12 & $40 / 60$ & 3 \\
S3 & 160 & 12 & $60 / 40$ & 6 \\
S4 & 160 & 6 & $40 / 60$ & 3 \\
S5 & 140 & 6 & $40 / 60$ & 3 \\
S6 & 160 & 6 & $60 / 40$ & 3 \\
S7 & 140 & 12 & $60 / 40$ & 6 \\
S8 & 140 & 6 & $60 / 40$ & 3 \\
\hline
\end{tabular}

Flexural strength was used as performance characteristics to deduce the optimal manufacturing parameters by using the fractional design and analysis of variance (ANOVA). The response data was analyzed using analysis of variance (ANOVA) technique at 0.05 levels of significance. Finally, degree of contribution of each significant factor was obtained so as to determine the level of its statistical importance in the model. The percentage (\%) contribution gives idea about the degree of contribution of the factors to the measured response [9].

\subsection{Preparation of the Beans Pod Ash Particles}

The uncrushed beans pods were cleaned with water and dried. After drying, the beans pods were packed in a graphite crucible and fired in a control atmosphere muffle electric furnace at a temperature of $1200^{\circ} \mathrm{C}$ for 5 hours to form carbonized beans pod particles. The particle size analysis of the beans pod particles was carried out in accordance with ASTM-60. $100 \mathrm{~g}$ of the beans pod particles was placed into a set of sieves arranged in descending order of fineness and shaken for 15 minutes which is the recommended time to achieve complete classification. The weight retained on $100 \mu \mathrm{m}$ was used in this research [8]. Mini Pal compact energy dispersive X-ray spectrometer (XRF) was used for the elemental analysis of the carbonized beans pod particles. The system was controlled by a PC running the dedicated Mini Pal analytical software. The XRD analysis of the beans pod ash particles was carried out to determine the various phase distribution in the samples. The analysis was carried out using Philips X-ray diffractometer at the department of chemical and metallurgical engineering, University of Witwatersrand, Johannesburg South Africa. The X-ray diffractograms was taken using CuK $\alpha$ radiation at scan speed of $3 \% \mathrm{~min}$.

\subsection{Sample Preparation}

The RLDPE matrix and the bean pod particles were pre-dried prior to the compounding. The mixture was compounded using co-rotating twin extruder (APV Baker Ltd. England, Model: MP19PC) with L/D ratio of the screw of 25:1. Mixing speed of $60 \mathrm{rpm}$ was maintained for all the compositions [3] [4]. Metal molds were used in the production of the composite samples. The mixture was placed in a $400 \mathrm{~mm} \times 400 \mathrm{~mm}$ rectangular mould and pressed to a thickness of $4 \mathrm{~mm}$. At the end of press cycle the composites were removed from the press for cooling. The design formulation in Table 2 was used in the production of the composites.

\subsection{Microstructural Analysis}

The microstructure of the bean pod particles and surface morphology of the composites were studied using a JOEL JSM 5900LV Scanning Electron Microscope equipped with an Oxford INCATM Energy Dispersive Spectroscopy system. The samples were firmly held on the sample holder using a double-sided carbon tape before putting them inside the sample chamber. The SEM was operated at an accelerating voltage of $20 \mathrm{Kv}$. The digitized images were recorded.

\subsection{Mechanical Test}

Before the test the samples were cut from the composites for the mechanical test in according with the recom- 
mended Standard. Prior to the test, all the samples were conditioned at a temperature of $23^{\circ} \mathrm{C} \pm 2^{\circ} \mathrm{C}$ and relative humidity of 65\% according to ATM D618-08 [3].

The flexural test was used for the optimization analysis. Flexural tests were performed on housefield tensometer testing machine. A three point bending configuration was used with specimen nominal dimension of 150 $\times 50 \times 4 \mathrm{~mm}$ and a span of $96 \mathrm{~mm}$. The load was applied continuously throughout the test at a uniform rate 3 $\mathrm{mm} / \mathrm{min}$ [10]. The flexural strength was determined in accordance with ASTM D790-10 Standard Test Methods for Flexural Properties of Unreinforced and Reinforced Plastics and Electrical Insulating Materials. For tensile tests the composite samples were cut into dumb-bell shape with cross sectional dimension of $135 \mathrm{~mm} \times 14 \mathrm{~mm}$ $\times 4.0 \mathrm{~mm}$ in accordance with ASTMD638-10 Standard Test Method for Tensile Properties of Plastics. The tests were performed at a constant strain rate of $0.5 \mathrm{~mm} / \mathrm{min}$. Hardness of the composites was determined by Rockwell hardness machine (BS903 part A 26) [8] using $1.56 \mathrm{~mm}$ steel ball indenter, minor load of $10 \mathrm{~kg}$, major load of $100 \mathrm{~kg}$ and hardness of 101.2HRB as the standard block. The impact test of the composites sample was conducted using a fully instrumented Avery Denison test machine. Charpy impact tests were conducted on unnotched samples. Standard square impact test sample of measuring $75 \times 10 \times 4 \mathrm{~mm}$ was used in accordance with ASTMD256-10 Standard Test Methods for Determining the Chary Pendulum Impact Resistance of Plastics [7].

\section{Results and Discussion}

\subsection{Characterization of the Bean Pod Ash Particles}

The XRF chemical composition of the carbonized beans pod ash particles is represented in Table 3. XRF analysis confirmed $\mathrm{SiO}_{2}, \mathrm{Al}_{2} \mathrm{O}_{3}, \mathrm{MgO}$ and $\mathrm{Fe}_{2} \mathrm{O}_{3}$ were found to be major constituents of the ash. Silicon dioxide, iron oxide and alumina are known to be among the hardest substances [8]. Some other oxides viz. $\mathrm{CaO}, \mathrm{K}_{2} \mathrm{O}, \mathrm{Na}_{2} \mathrm{O}$ were also found to be present in traces.

The XRD pattern of the bean pod ash particles revealed that, the major diffraction peaks are $44.05^{\circ}, 36.06^{\circ}$, $45.12^{\circ}, 47.21^{\circ}$ and $26.12^{\circ}$ and their inter-planar distance are $2.38 \AA, 2.25 \AA, 3.31 \AA$ and $2.62 \AA$. Their relative intensity of X-ray scattering are 10.02, 11.79, 44.31, 1.36 and 100.00 and phases at these peaks are Carbon (C), Quartz syn $\left(\mathrm{SiO}_{2}\right)$, Iron Silicon (Fe $1.34 \mathrm{Si}$ 0.66), Iron Carbide $\left(\mathrm{Fe}_{7} \mathrm{C}_{3}\right)$ and Moissanite $(\mathrm{SiC})$ respectively (Figure 1). The result showed that silicon carbon had the highest percentage of all the compound and element present as revealed by the XRD analysis. This is similar to results obtained in other biomass ash [8] [10].

Morphology of the bean pod ash particles by SEM/EDS is showed in Figure 2. Bean pod ash particles were observed to be solid in nature, but irregular in size. Some spherical shape particles can also be seen (see Figure 2).

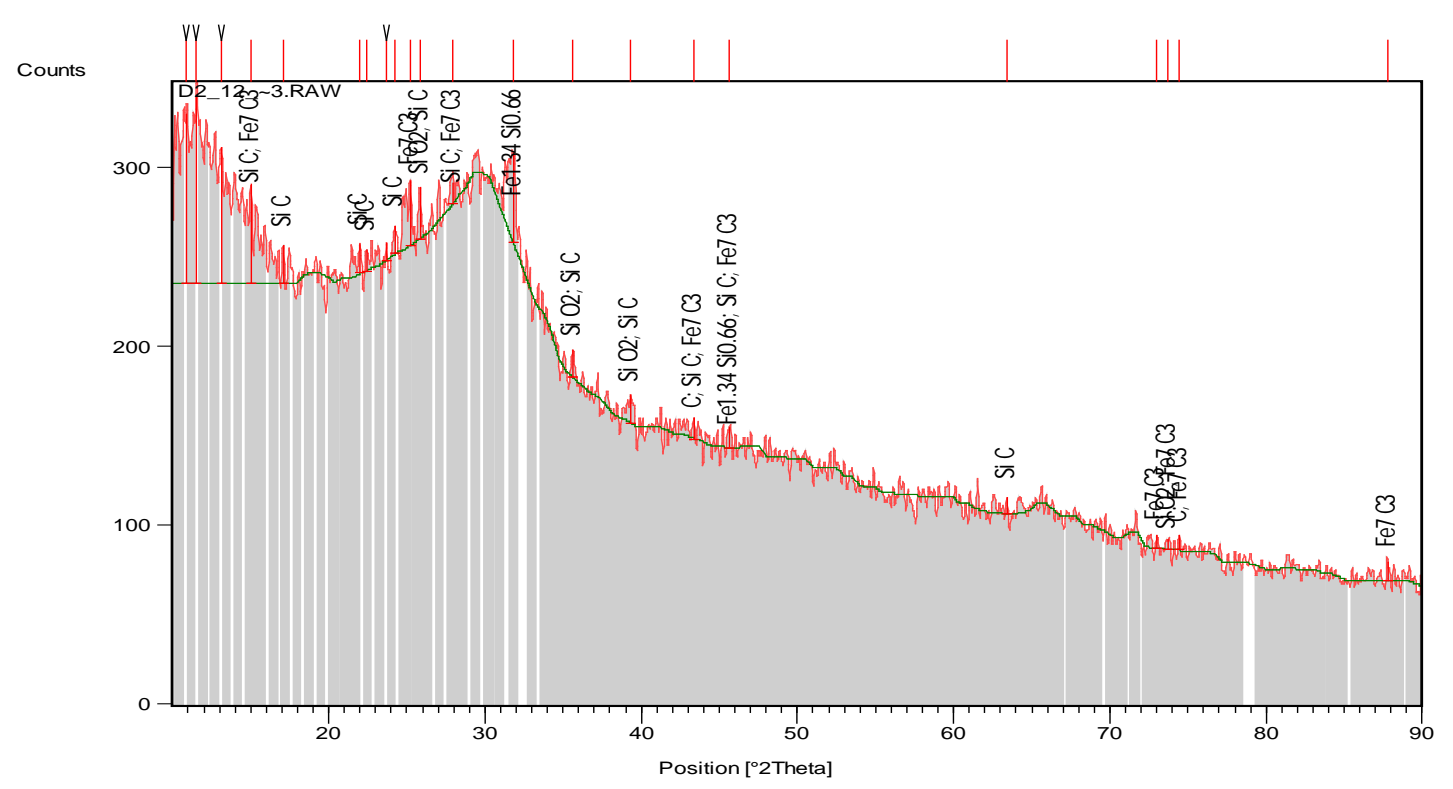

Figure 1. XRD Spectrum of carbonized bean pod particles. 


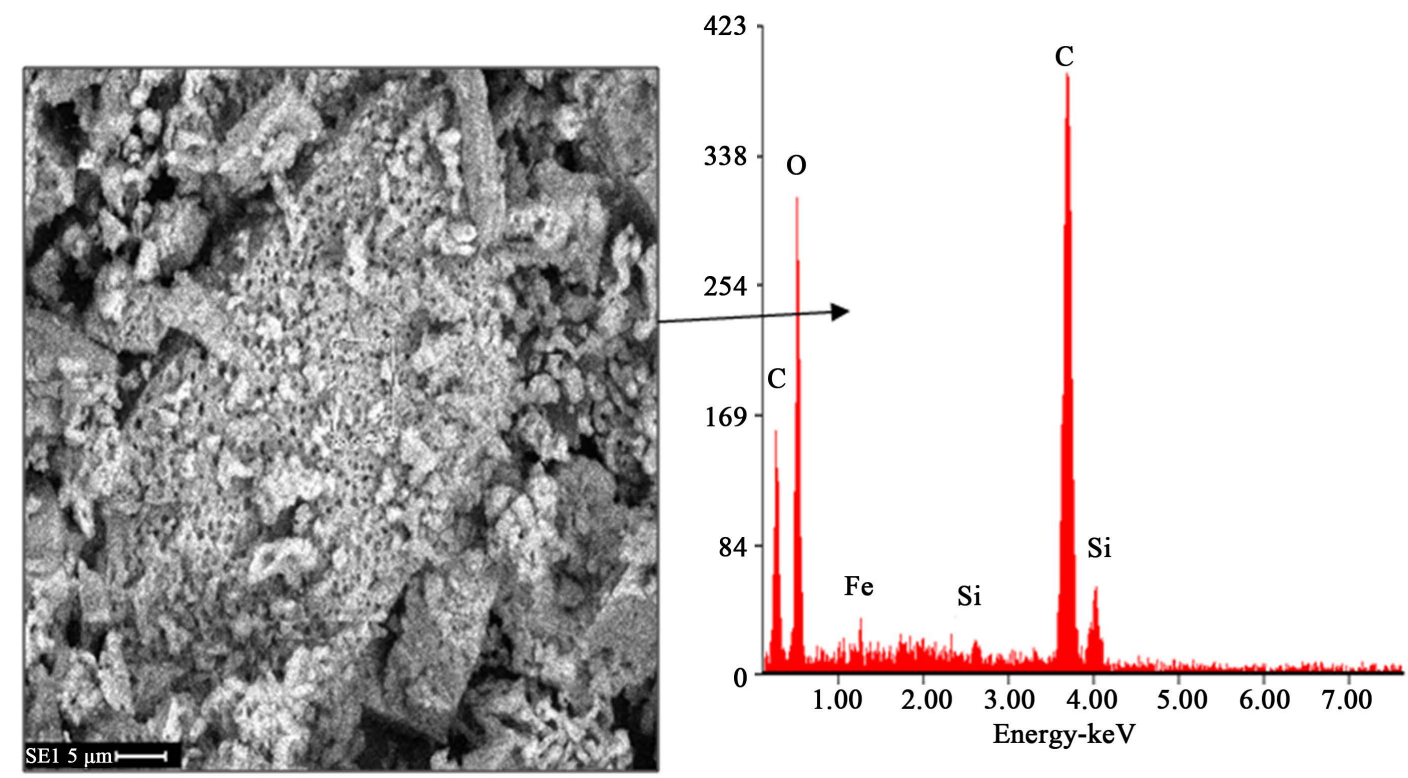

Figure 2. SEM/EDS of carbonized bean pod particles.

Table 3. Composition of the beans pod ash particles.

\begin{tabular}{cccccccccc}
\hline Oxide & $\mathrm{SiO}_{2}$ & $\mathrm{Al}_{2} \mathrm{O}_{3}$ & $\mathrm{Fe}_{2} \mathrm{O}_{3}$ & $\mathrm{CaO}$ & $\mathrm{MgO}$ & $\mathrm{Na}_{2} \mathrm{O}$ & $\mathrm{K}_{2} \mathrm{O}$ & $\mathrm{L} \mathrm{OI}$ \\
\hline wt\% & 80.24 & 0.5 & 15.67 & 3.0 & 0.6 & 0.24 & 0.32 & 9.5 \\
\hline
\end{tabular}

\subsection{Factorial Design Result for Optimization of the Flexural Strength}

For the optimization of the flexural strength, the upper level and the lower level of each variable along with their coded values used in this investigation are shown in Table 1 . The $2^{4-1}$ fractional factorial experimental design plan and the results obtained for the flexural strength at the different levels of the variable are shown in Table 4. The respond variables, in each trial, represent the average of three measured data at identical experimental conditions.

The model equation was obtained after calculating each of the coefficients of Equation (2) using Table 4 . The developed model equation for the processing of the composites can be expressed as:

$$
\text { Flexural strength }(F)=+6.19-1.02 * A+0.65 * B-0.88 * C-0.17 * A * C
$$

From Equation (3) it was observed that the coefficient of $A$ (temperatures) is negative, that of $B$ (time) is positive, that of $C$ (reinforce/polymer) is negative and the interaction between AC is also negative. These mean that by increasing the temperature from $140^{\circ} \mathrm{C}$ to $160^{\circ} \mathrm{C}$, the flexural strength decreased by -1.02 . Again, by increasing the time from 6 to 10 minutes increased the flexural strength by 0.65 , while by increasing the reinforcer from 40 to 60 wt\% also decreased the flexural strength by -0.88 and by increasing the temperatures and reinforcer at the same time decreased the flexural strength by -0.17 . These explanations can be seen clearly in Figure 3 and Figure 4. From Figure 3 and Figure 4, it can be seen that the flexural strength of the compposites are highly influenced by the reinforcer and temperature. For example as reinforcer increased from 40 to $60 \mathrm{wt} \%$, the flexural strength also decresased (see Figure 3 and Figure 4). However, as the temperature decreased from $160^{\circ} \mathrm{C}$ to $140^{\circ} \mathrm{C}$ the flexural strength increased (see Figure 4). The estimated response surface indicate optimized composite flexural strength at $40 \mathrm{wt} \% \mathrm{CBPp}, 140^{\circ} \mathrm{C}, 12$ minutes and $6 \mathrm{Mpa}$.

Substituting the coded values of the variables for any experimental condition in Equation (3), the flexural strength for the composites can be calculated. Figure 5 shows the predicted values along with the actual experimental values in different experimental conditions.

It is evident from Figure 5 that the actual experimental values are in close proximity with the predicted values. These facts suggested reasonably good reliability of the equation to predict the flexural strength of the composites within the selected experimental domains with error less than $2 \%$. 


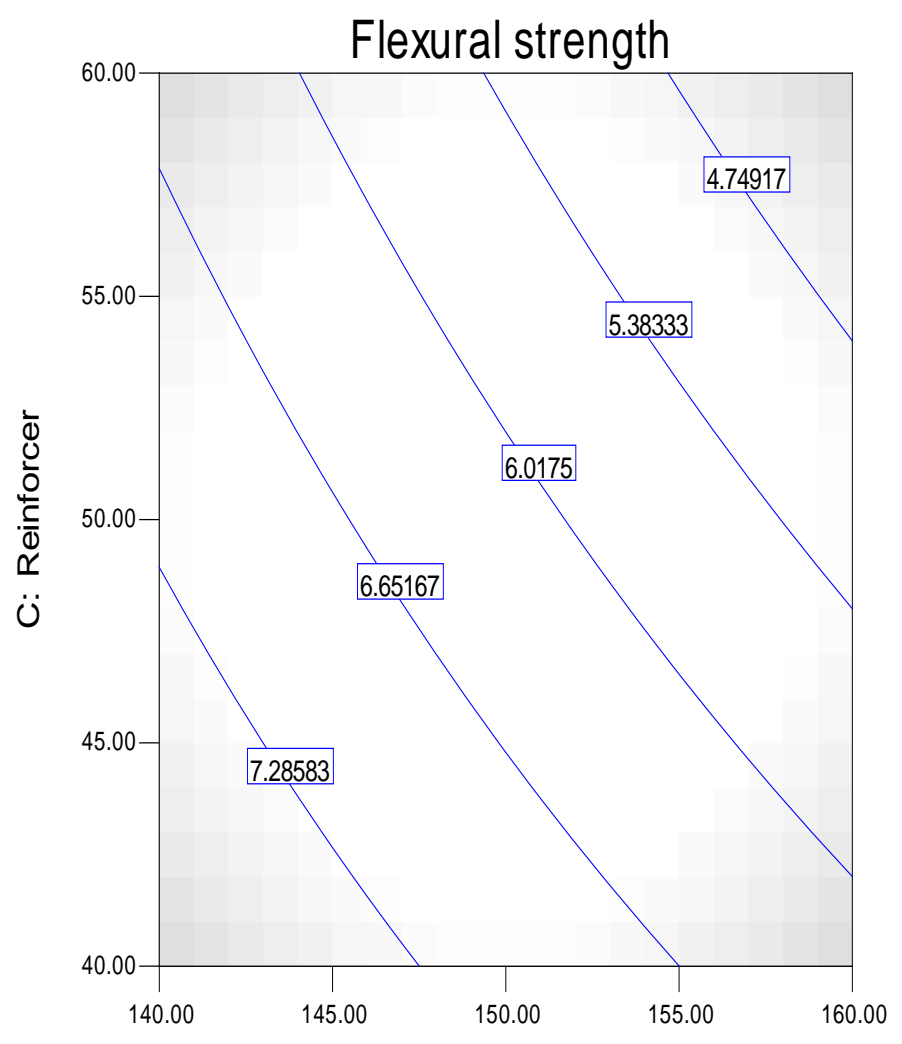

A: Temperatures

Figure 3. Variation of flexural strength with interaction of temperature and reinforcer.

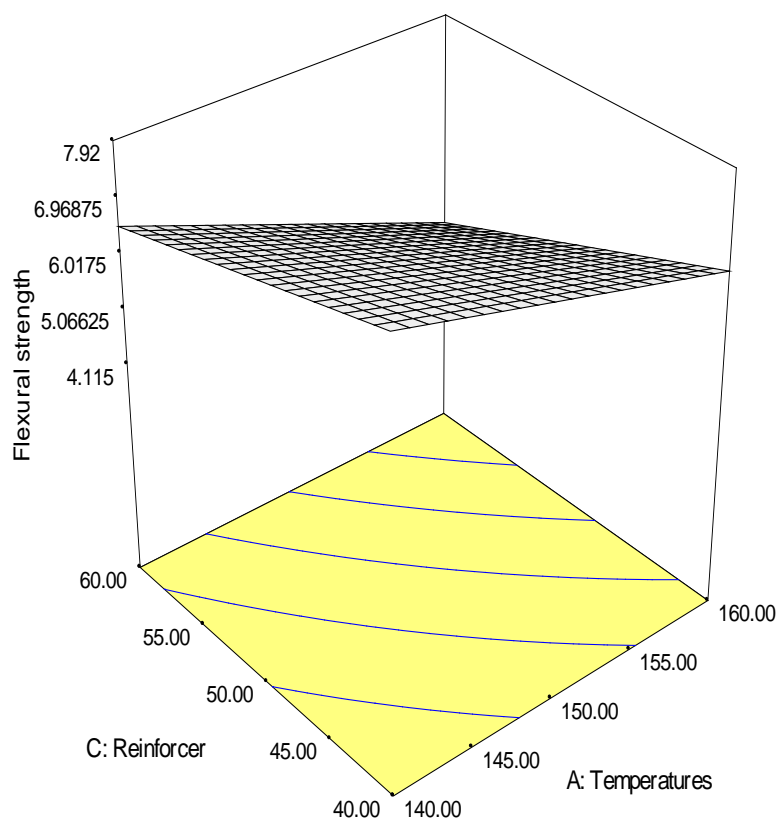

Figure 4. Contour graph of flexural strength with temperature and reinforcer. 


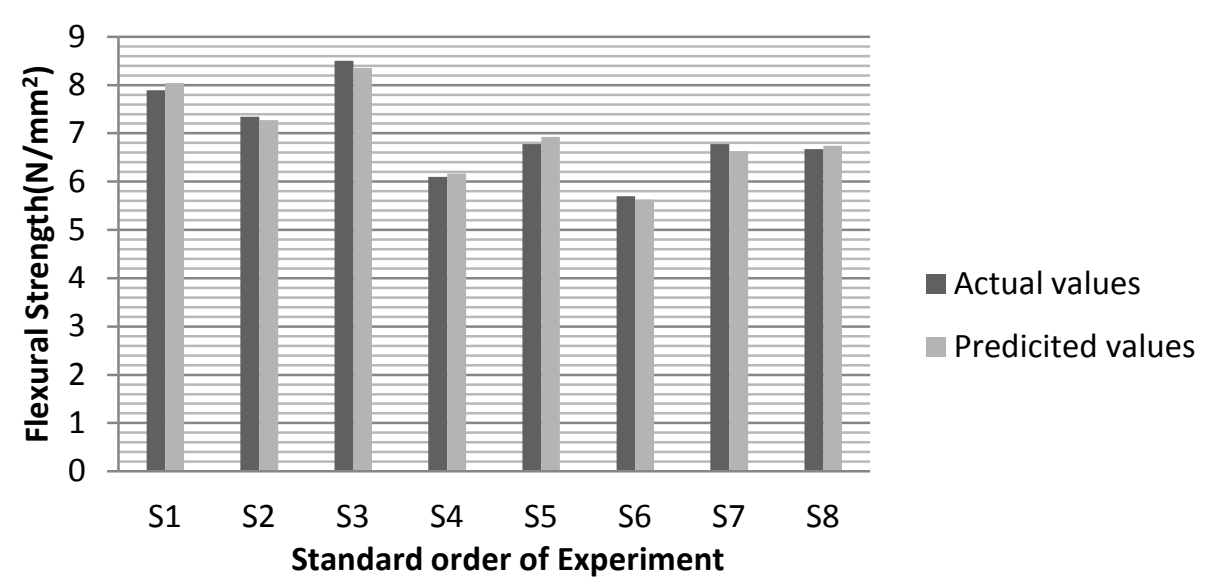

Figure 5. Variation of the flexural strength with experimental numbers.

Table 4. Expanded plan matrix for fractional factorial design.

\begin{tabular}{ccccccccccc}
\hline $\mathrm{S} / \mathrm{n}$ & $\mathrm{x}_{0}$ & $\mathrm{~A}$ & $\mathrm{~B}$ & $\mathrm{C}$ & $\mathrm{D}$ & $\mathrm{AB}$ & $\mathrm{AC}$ & $\mathrm{AD}$ & $F$ \\
\hline 1 & 1 & 1 & -1 & 1 & -1 & -1 & 1 & -1 & 5.70 & 5.67 \\
2 & 1 & 1 & -1 & -1 & 1 & -1 & -1 & 1 & -1 & \\
3 & 1 & 1 & 1 & -1 & -1 & 1 & -1 & -1 & -1 & 6.79 \\
4 & 1 & -1 & 1 & 1 & -1 & -1 & -1 & 1 & 7.50 & 7.34 \\
5 & 1 & -1 & -1 & -1 & -1 & 1 & 1 & 1 & & 5.5 \\
6 & 1 & -1 & -1 & 1 & 1 & 1 & -1 & -1 & & \\
7 & 1 & -1 & 1 & -1 & 1 & -1 & 1 & -1 & & 8.50 \\
8 & 1 & 1 & 1 & 1 & 1 & 1 & 1 & 1 & 5.67 \\
\hline
\end{tabular}

ANOVA was used to determine the design parameters significantly influencing the flexural strength. The values of $F$ calculated ( $F=$ Fishers distribution) were compared with $F$ critical. $F$ distribution critical values for degrees of freedom $(1,7)$ at 95\% confidence level (see Table 5). For the ANOVA of the composites it was observed that Model F-value of 38.32 implies the model is significant. There is only a $0.66 \%$ chance that a "Model F-Value" this large could occur due to noise. Values of "Prob > F" less than 0.0500 indicate model terms are significant. In this case $A$ (temperature), $B$ (time), $C$ (reinforcer) are significant model terms. Values greater than 0.1000 indicate the model terms are not significant. The "Pred R-Squared" of 0.8635 is in reasonable agreement with the “Adj R-Squared” of 0.9552. “Adeq Precision” measures the signal to noise ratio.

The optimum values of flexural strength was predicted at the selected levels of significant parameters and their optimum levels have already been selected as $A\left(140^{\circ} \mathrm{C}\right), B(12$ minutes), $C$ (40 wt\% CBPp) and $D(6 \mathrm{Mpa})$ for the composites (see Table 6). Also the results of others properties at optimized condition are shown in Table 7.

\subsection{Properties of Optimal Composites}

\subsubsection{Morphology of the Composites}

SEM was used to study the morphology of RLDPE/bean pod ash particles composites. Figure 6 shows the SEM micrograph of the RLDPE, while Figure 7 shows the SEM micrograph of the composites at optimized condition. Morphological study showed that the bean pod ash particles as a reinforcement had smooth spherical surfaces and more surface area for interaction. There is a fair dispersion of bean pod particle in the polymer matrix. The interaction between the particles and the matrix was also good as shown in the SEM in Figure 7. Morphological results clearly show that there is proper intimate mixing of bean pod ash particles with the polymer resin in the 


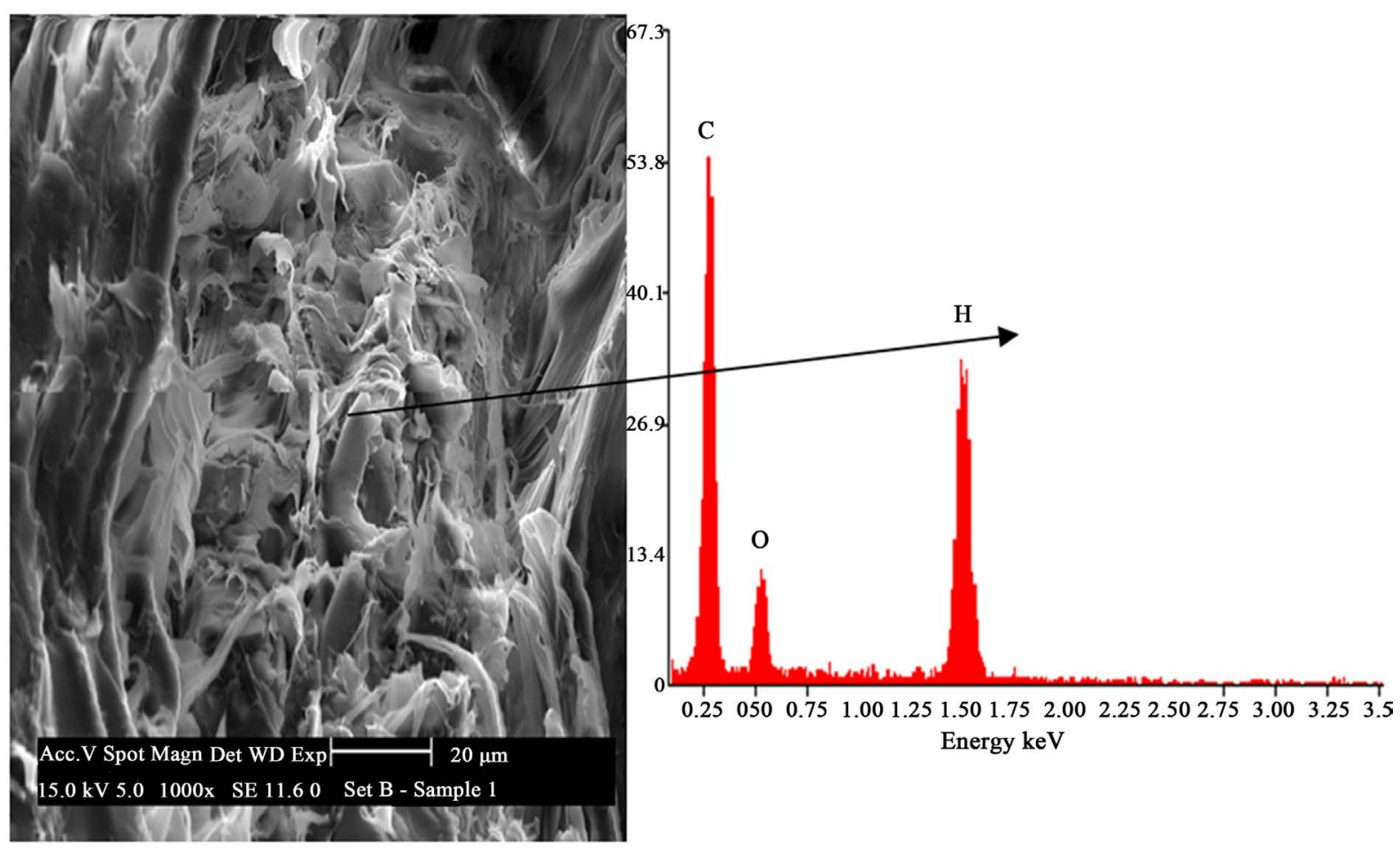

Figure 6. SEM/EDS of the RLDPE matrix.

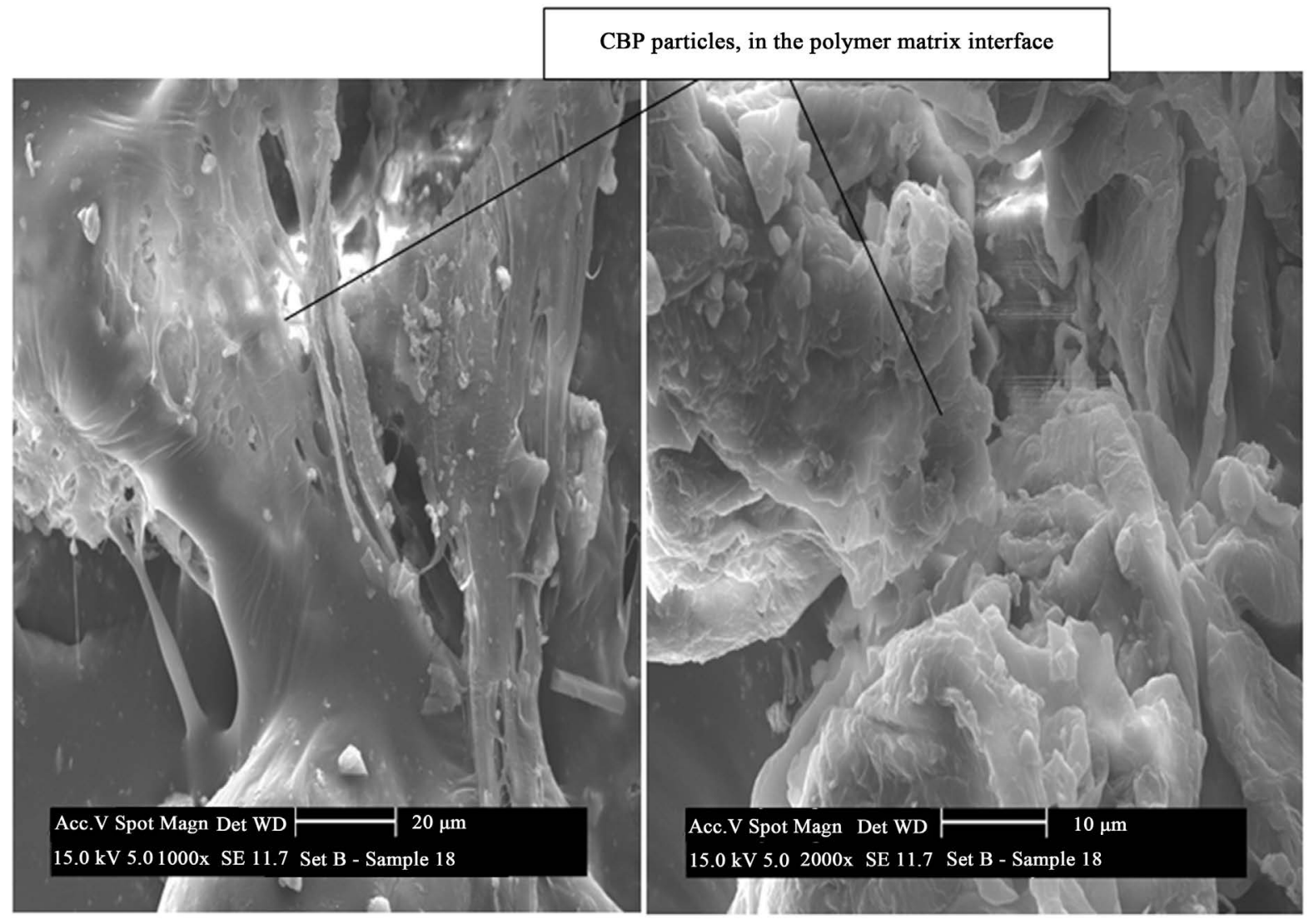

Figure 7. SEM of the optimized codition of CBPp composites. 
Table 5. ANOVA for selected factorial model.

\begin{tabular}{ccccccc}
\hline & \multicolumn{5}{c}{ Flexural strength for composites } \\
\hline Source & Sum of squares & DF & Mean square & $F_{\text {value }}$ & P $_{\text {value }}$ & Remarks \\
\hline Model & 18.13 & 4 & 4.53 & 38.32 & 0.0066 & Significant \\
A & 8.30 & 1 & 8.30 & 70.18 & 0.0036 & Significant \\
B & 3.34 & 1 & 3.34 & 28.24 & 0.0130 & Significant \\
C & 6.25 & 1 & 6.25 & 52.81 & 0.0054 & Significant \\
AB & 1.10 & 1 & 1.10 & 26.34 & 0.0559 & Not significant \\
AC & 0.24 & 1 & 0.24 & 2.04 & 0.2484 & Not significant \\
AD & 1.95 & 1 & 1.95 & 46.59 & 0.0508 & Not significant \\
Residual & 0.35 & 3 & 0.12 & & & \\
CorTotal & 18.49 & 7 & & & & \\
\hline
\end{tabular}

Table 6. Optimum levels of process parameters (flexural strength).

\begin{tabular}{|c|c|c|}
\hline \multirow{2}{*}{ Process parameter } & \multirow{2}{*}{ Parameter designation } & Optimal level \\
\hline & & CBPp \\
\hline Temperature $\left({ }^{\circ} \mathrm{C}\right)$ & $A$ & 140 \\
\hline Time (minuets) & $B$ & 12 \\
\hline Bean pod particles/polythene content (wt\%) & $C$ & $40 / 60$ \\
\hline Pressure (Mpa) & $D$ & 3 \\
\hline
\end{tabular}

Table 7. The results of others properties at optimized condition.

\begin{tabular}{|c|c|c|c|c|c|}
\hline Conditions & $\begin{array}{c}\text { Tensile } \\
\text { strength }\left(\mathrm{N} / \mathrm{mm}^{2}\right)\end{array}$ & $\begin{array}{c}\text { Compression strength } \\
\qquad\left(\mathrm{N} / \mathrm{mm}^{2}\right)\end{array}$ & $\begin{array}{c}\text { Bending } \\
\text { strength }\left(\mathrm{N} / \mathrm{mm}^{2}\right)\end{array}$ & $\begin{array}{c}\text { Impact } \\
\text { Energy }(\mathrm{J})\end{array}$ & $\begin{array}{c}\text { Hardness } \\
\text { values HRB }\end{array}$ \\
\hline RLDPE matrix & 3.90 & 13.00 & 7.10 & 4.30 & 2.81 \\
\hline CBPp composites & 6.25 & 18.25 & 4.51 & 2.65 & 10.67 \\
\hline
\end{tabular}

composites. Particles-matrix interface plays an important role in composite properties. A strong particles-matrix interface bond is critical for high mechanical properties of composites.

\subsubsection{Hardness Values}

The hardness of the composite reinforced with CBPp was greater than that of unreinforced and this is because the CBPp filler contains more carbon, has smaller particles and has given off all combined moisture resulting to an increase in the hardness of the composite. However the composites have higher hardness values than the matrix. For example the hardness values of 2.81 HRB and 10.67 HRB (see Table 7) were obtained for the matrix and optimized condition respectivly.

\subsubsection{Tensile Strength}

The tensile strength of the composites decreased slightly as the beans pod ash particles loading increased beyond $40 \mathrm{wt} \%$. It clearly indicates that addition of beans pod ash particles improve the load bearing capacity of the composites. Similar observations have been reported by Agunsoye et al. [11] for other fiber reinforced polymer composites. At the $40 \mathrm{wt} \%$ beans pod ash particles loading, there was fair interfacial bonding between the hydrophilic filler and hydrophobic matrix polymer, which led to increased in the tensile strength. Higher loading may have result to poor interfacial bonding between the particles and the RLDPE matrix. Since beans pod 
particles is hydrophilic in nature, its strong inter filler hydrogen bonding allows them to cling together, thus resisted dispersion of the filler, leading to weak interfacial bonding with consequent problems such as small void spaces and de-bonding in the resulting composite.

Nevertheless the tensile strength obtained in this study remained within acceptable levels for outdoor and indoor structural applications [3]. The tensile strength obtained at these optimum point is due to the stability of the filler to support stresses transferred from the polymer matrix [12]. Similar results are reported in previous work of [8].

\subsubsection{Compressive Strength}

Compressive properties of RLDPE matrix and composites are 13.00 and $18.25 \mathrm{~N} / \mathrm{mm}^{2}$ respectively (see Table 7). It is clear that the compressive strength of the composites increased with increase of beans pod ash particles in the polymer matrix. This may be due to the hardening of the matrix by beans pod ash particles [12].

\subsubsection{Impact Strength}

The impact strength decreases with increasing bean pod ash particles in the RLDPE matrix. This is mainly due to the reduction of elasticity of material due to filler addition and thereby reducing the deformability of matrix. An increase in concentration of filler reduces the ability of matrix to absorb energy and thereby reducing the toughness, so impact strength decreases. Also it is obvious that plastic deformation of the mixed polymer matrix and the non-deformable reinforcement is more difficult than the polymer matrix. These results are in agreement with the work of other researchers [12].

The tensile properties are in agreement with the results obtained from the analysis of the hardness and impact strength. The increase in hardness is related with high tensile modulus and the increasing amount of hard bean pod ash particles in the RLDPE matrix. On the other hand, as can be suggested from the impact test, the elastic behavior of the matrix proportionately varies with the addition of the bean pod ash particles. As the loading of bean pod ash fillers increases, the ability of the composites to absorb impact energy decreases since there is less ratio of the RLDPE matrix to fillers. However the results obtained remained within the standard level for biocomposites [1].

\section{Conclusions}

In this present work, some mechanical and microstructural studies have been carried out on the RLDPE/bean pod ash particles composite. From the results and discussion presented in the preceding section, the following conclusions can be made:

1) RLDPE reinforced with bean pod particles was successfully produced with casting method.

2) The optimum values of flexural strength were obtained at $140^{\circ} \mathrm{C}, 12$ minutes, $40 \mathrm{wt} \% \mathrm{CBPp}$ and $6 \mathrm{Mpa}$.

3) The hardness values and tensile strengths of the composite are increased by the addition of beans pod ash particles to RLDPE composites.

4) Compressive properties of RLDPE matrix and composites are 13.00, 16.90 and $18.25 \mathrm{~N} / \mathrm{mm}^{2}$ for the matrix, UBPp and CBPp composites.

5) The fairly uniform distribution of the bean pod ash particles in the microstructure of the composites is the major factor responsible for the improvement in the mechanical properties.

6) The obtained results of the developed composites have shown that the beans pod waste could be used as a biodegradable eco-friendly reinforcement.

\section{References}

[1] Saxena, M., Morchhale, R.K., Asokan, P. and Prasad, B.K. (2002) Plant Fiber-Industrial Waste Reinforced Polymer Composites as a Potential Wood Substitute Material. Journal of Composite Materials, 42, 367-384.

[2] Berhane, Z. (1999) Performance of Natural Fibre Reinforced Mortar Roofing Tiles. Materials and Structures, 27, 347352. http://dx.doi.org/10.1007/BF02473427

[3] Sun, X.F., Sun, R.C. and Sun, J.X. (2004) Comparative Study of Alkali-Acidic Organic Soluble Hemicelluloses Polysaccharides from Sugarcane Bagasse. Poly, 15, 67-69.

[4] Luo, S. and Netravali, A.N. (1999) Mechanical and Thermal Properties of Environment-Friendly “Green” Composites Made from Pineapple Leaf Fibers and Poly(Hydroxybutyrate-Co-Valerate) Resin. Polymer Composites, 20, 367-378. 
http://dx.doi.org/10.1002/pc.10363

[5] Nakamura, Y., Yamaguchi, M., Okubo, M. and Matsumoto, T. (1990) Effect of Particle Size on Impact Properties of Epoxy Resin Filled with Angular Shaped Silica Particles. Poly, 32, 2976-2979. http://dx.doi.org/10.1016/0032-3861(91)90195-O

[6] Bijwe, J., Logani, C.M. and Tewari, U.S. (2001) Influence of Fillers and Fibre Reinforcement on Abrasive Wear Resistance of Some Polymeric Composites. Wear, 138, 77-92. http://dx.doi.org/10.1016/0043-1648(90)90169-B

[7] Ksman, K. and Clemons, C. (1998) Mechanical Properties and Morphology of Impact Modified Polypropylene-Wood Flour Composites. Journal of Applied Polymer Science, 67, 1503-1513. http://dx.doi.org/10.1002/(SICI)1097-4628(19980228)67:9<1503::AID-APP1>3.0.CO;2-H

[8] Sarki, J., Hassan, S.B., Aigbodion, V.S. and Oghenevweta, J.E. (2011) Potential of Using Coconut Shell Particle Fillers in Eco-Composite Materials. Journal of Alloys and Compounds, 509, 2381-2385. http://dx.doi.org/10.1016/j.jallcom.2010.11.025

[9] Miller, I. and Freund, J.E. (2001) Probability and Statistics for Engineers. Prentice Hall India Ltd., India, 125-140.

[10] Kandachar, P. and Brouwer, R. (2002) Applications of Bio-Composites in Industrial Products. Materials Research Society Symposium Proceedings, 702, 101-112.

[11] Agunsoye, J.O., Aigbodion, V.S., Talabi, S.I. and Moses, Y.E. (2013) Journal of Metallurgical Engineering (ME), 2, 107-114.

[12] Supri, A.G. and Lim, B.Y. (2009) Effect of Treated and Untreated Filler Loading on the Mechanical, Morphological, and Water Absorption Properties of Water Hyacinth Fibers-Low Density Polyethylene Composites. Journal of Physical Science, 20, 85-96. 